\title{
The Impact of Information Technology Capabilities of Manufacturing Enterprises on Innovation Performance: Evidences from SEM and fsQCA
}

\author{
Yizhou Chu ${ }^{1}$, Maomao Chi ${ }^{1, *}$, Weijun Wang ${ }^{2}$ and Bo Luo ${ }^{1}$ \\ 1 School of Information Management, Central China Normal University, Wuhan 430079, China; \\ chuyizhou1016@163.com (Y.C.); luob@mail.ccnu.edu.cn (B.L.) \\ 2 Key Laboratory of Adolescent Cyberpsychology and Behavior, Ministry of Education, \\ Central China Normal University, Wuhan 430079, China; wangwj@mail.ccnu.edu.cn \\ * Correspondence: chimaomao@aliyun.com
}

Received: 2 October 2019; Accepted: 21 October 2019; Published: 25 October 2019

\begin{abstract}
With the development of national strategies (such as Industrial 4.0 and Made in China 2025), how to build digital enterprises and cultivate innovation capabilities of enterprises has become a critical problem to Chinese manufacturing enterprises. However, the literature on the specific path of information technology (IT) capabilities to the innovation of enterprises is still lacking a body of relevant empirical research. In particular, it has not yet thought to explore the information technology capabilities, digital transformation, and then innovation performance of manufacturing enterprises. By performing a questionnaire investigation for 138 Chinese manufacturing enterprises, this study adopted both a fuzzy-set qualitative comparative analysis (fsQCA) and structural equation modeling (SEM) to explore the set relations of the conjunctions and conditions and the statistical associations by studying the relationships among information technology capabilities, digital transformation and innovation performance. The results show that the positive impacts of information technology capabilities on the process innovation performance and the digital transformation, as well as the positive impacts of digital transformation on both process innovation performance and product innovation performance. Specifically, digital transformation takes on a new function of partial mediation of IT capabilities and process innovation performance, and digital transformation functions as a complete mediator for IT capabilities and product innovation performance. The combinations of causal recipes related to innovation performance are provided by a fuzzy-set qualitative comparative analysis (fsQCA). Through the analyses of SEM and fsQCA, this research develops the formation mechanisms of both process innovation performance and product innovation performance, and provides guidance for both IT and innovation management of manufacturing enterprises in China.
\end{abstract}

Keywords: manufacturing enterprises; IT capabilities; innovation performance; digital transformation; fuzzy-set qualitative comparative analysis; structural equation modeling

\section{Introduction}

Industrial circles, academic circles and governments of major industrial countries have recently and rapidly reached some level of agreement on the grand visions of Industry 4.0, such as Made in China 2025 formulated by China and the manufacturing renaissance advocated by the USA [1-3]. The implementation of relevant policies of Industry 4.0 is expected to revitalize China's real economy, especially her manufacturing industry. The key to carrying out Industry 4.0 in traditional manufacturing enterprises is to improve the digital level of the value chain, namely, realizing the digital transformation (DT) of enterprises [4,5] (DT in this study highlights that manufacturing enterprises realize digitalization 
and automation in organizational operation by using digital techniques, like cloud computing, big data, and the social platforms (Bharadwaj et al., 2013).). Enterprises which have realized DT can rapidly achieve product innovation and process innovation and meet personalized and changeable demands of customers, thus forming sustainably developing competitiveness. For example, the Haier Group building itself, a digital enterprise by means of Teamcenter (a full-life cycle management platform of model-based enterprise (MBE)) improves efficiency for new product development and supports global design collaboration and the operation of its supply chain. Therefore, how to build digital enterprises and cultivate innovation capabilities of enterprises has become an urgent practical problem for traditional manufacturing enterprises as they take the road to Industry 4.0.

The existing literature [6-9] generally considered that information technology or digital technology can promote firm innovation (The innovation performance in this research mainly refers to technological innovation performance. The specific contents include PSI and PDI performances (Daft, 1978; Nambisan et al., 2017), while it does not involve management and organizational change caused by non-technical factors.). For instance, from the perspective of information processing, information technology (IT) can help enterprises quickly obtain relevant information and provide an information base for enterprise innovation. Furthermore, IT can also effectively manage innovation processes [10]. However, the digital age is a turning point for innovation research [11-13] and brings new opportunities for studying innovation and technology management [14,15]. In the background of Made in China 2025 and Internet+, many traditional manufacturing companies have begun to make use of the original informatization (such as IT capabilities), expecting to realize DT, thus further rapidly realizing innovation $[4,16]$. Some studies also found that enterprises which have carried out DT in business operation processes can introduce new ideas and innovation measures [17]. However, there are only a few studies that explored DT empirically and studied the effects of manufacturing enterprises (especially in the emerging economies) carrying out DT through IT capability, thus forming innovation performance.

At present, Made in China 2025, as themed by Internet + intelligent manufacturing, has been gradually promoted among manufacturing industries in China. In the overall context of the Made in China 2025 strategy, it is necessary for China's manufacturing enterprises to realize DT and innovation performance of enterprises through IT. This study explores the process by which manufacturing enterprises in China drive DT by building IT capabilities, thus realizing innovation performance. Based on these, the corresponding policies and management implications are found. This is of great theoretical and practical significance for helping manufacturing enterprises realize DT and innovation performance. On this basis, by taking manufacturing enterprises in China as research objects, this study explores influence mechanisms among IT capabilities, DT and innovation performance based on the literature related to IT capabilities, digital business strategies and innovation management. This study analyzed the data through the use of the fuzzy-set qualitative comparative analysis (fsQCA) and structural equation modeling (SEM) for determining both set of relations and statistical associations. This research found that DT plays a partial mediating role between IT capabilities and process innovation performance (PSIP) of enterprises, while it has a complete mediating role between enterprises' IT capabilities and product innovation performance (PDIP). Therefore, this verifies the key role of DT in the formation of innovation performance of enterprises through IT capabilities. This study is beneficial to deepening the knowledge and understanding of manufacturing enterprises as they strive to realize innovation performance through IT capabilities, and provides management and policy suggestions for IT and innovation management practices of enterprises.

\section{Literature Review and Research Hypotheses}

\subsection{Information Technology Capabilities and Innovation Performance}

IT capabilities are considered as the abilities of an enterprise to deploy IT resources and other enterprise resources [18]. The resource-based view (RBV) of a firm illustrates that enterprises need to 
form IT capabilities by integrating IT infrastructure, IT human resources, and IT-enabled intangible resources, so as to obtain sustainable competitive advantages $[18,19]$. However, due to homogeneity and ubiquitous best practice schemes (i.e., enterprise resource planning (ERP) system), scholars specializing in information systems begin to question the direct impacts of IT capabilities on firm performance [10]. The literature holds that the isolated capabilities or resources of an enterprise do not have value, while exhibiting value when they have the opportunity to be used [20]. Under the background of digital business, IT capabilities can help enterprises establish digital links in the activities and entities of the value chain $[14,16]$. Therefore, IT capabilities can enable enterprises to respond to constantly changing market demands by using digital technology. In previous literature, IT capabilities were generally measured in a multi-dimensional manner [21]. In this study, IT capabilities from the research results of prior literature were used which include three main dimensions: IT infrastructure (ITI) capability, IT business spanning (ITB) capability, and an IT proactive stance (ITP) [21]. Among them, ITI capability emphasizes the ability of an enterprise to deploy related hardware platforms and software systems. ITB capability stresses that an enterprise can effectively support business objectives through IT resources. Furthermore, ITP focuses on how an enterprise can proactively utilize existing IT resources to create business opportunities.

Due to the differences in research perspectives, there is no uniform concept of innovation in the literature [22], however, it is still widely accepted that innovation is a new idea or behavior adopted by enterprises, such as systems, strategies, devices, processes and products or services [23]. According to different criteria, innovation can be classified into distinct types. In line with prior research [22], innovation falls into two types: incremental and radical. The former means that the goal of innovation is achieved through continuous and incremental small innovations, while the latter refers to rapid and storm-like innovations. The radical innovation is characterized by strong impacts on existing systems and a significant degree of innovation, but the process is not very long and is generally completed quickly. In accordance with the dual-core model of innovation [24], technology and management innovations are further classified. The management innovation involves new policies and organizational forms, while technology innovation mainly includes process innovation (PSI) and product innovation (PDI). PDI indicates development and introduction of new or improved products and/or services that are successful in the market, while PSI involves adopting new or improved processes and methods, such as manufacturing and distribution. As innovation performance involved in this study highlights technological innovation performance $[25,26]$, this study focuses on two perspectives of innovation performance (both PSIP and PDIP).

In the increasingly fierce competitive market environment, manufacturing enterprises need to use emerging digital technologies (such as the Internet of Things and cloud computing technology) to realize PSI and PDI, thus obtaining sustainable competitive advantages. IT capabilities can help enterprises integrate internal and external resources to provide a resource base for PSI and PDI, and effectively manage and coordinate specific process of innovation, thus ensuring innovation activities among enterprises [27]. For instance, previous literature showed that enterprises can effectively manage innovation process (including five stages from generation of an idea to final commercialization) through IT [28], so as to promote technological innovation performance. Therefore, IT capabilities can promote technological innovation performance which includes PSIP and PDIP. On this basis, the following hypotheses are proposed:

Hypothesis 1a (H1a). IT capabilities are positively associated with PSIP.

Hypothesis $\mathbf{1 b}(\mathbf{H 1} \mathbf{b})$. IT capabilities are positively associated with PDIP. 


\subsection{Information Technology Capabilities and Digital Transformation}

It has been a challenging for the traditional organizational structure of enterprises to adapt to the requirements of the market, and traditional enterprises that have realized DT can accomplish innovation and obtain sustainable competitive advantages [29]. As shown in a recent Forbes survey (Forbes Insight Report. 2016. “How Digital Transformation Elevates Human Capital Management: Turning Talent into a Strategic Business Force", http://www.forbes.com/forbesinsights.), it is estimated by $42 \%$ of the chief executive officers (CEOs) and chief information officers (CIOs) that many digital business strategies or DT will be involved in their work in the next five years. Moreover, $31 \%$ of respondents believe that the platform transformation is expected to extend across the entire value chain of the organization. Many traditional enterprises have begun to plan and implement DT and innovation, aiming to improve sustainable competitiveness of enterprises [30]. For example, Rongchang, a laundry chain brand in China has transformed to an e-washing paradigm and the Haier Group has broken up into small, micro-organizational autonomous entities. DT refers to the transformation of an enterprise using digital technologies, such as big data, cloud computing, and social platforms and is a process in which traditional manufacturing enterprises break the mold and seek innovation and changes [14]. DT is on the basis of utilizing digital techniques, thus changing value creation and business processes of enterprises [29]. DT can promote enterprises to integrate digital technologies with operational processes, further promoting customer participation in digital innovation activities [31]. For example, to strengthen the sense of participation, Xiaomi Technology Co., Ltd. has created a very distinctive Mi Global Home (a social platform) to establish a community, enabling active interaction with fans, so as to produce innovative products and services that meet the personalized needs of customers.

Prior literature also demonstrated that IT capabilities can further facilitate a digital business strategy [32,33] and DT strategy [34]. For instance, Amazon has promoted the formation of the DT strategy for relevant activities on the value chain for many years through its established IT capabilities. Furthermore, enterprises which possess relevant IT resources are more likely to develop from the application of information systems to specific digital technologies, such as big data analysis, and social platforms [7]. Therefore, enterprises with a high level of IT capabilities can effectively carry out DT and rapidly realize business progress re-engineering and the production of digital products. Based on the above, this research considered that enterprises with higher IT capabilities are more conducive to DT. The following hypothesis is proposed:

Hypothesis 2 (H2). IT capabilities are positively associated with the degree of DT.

\subsection{Digital Transformation and Innovation Performance}

DT can fully connect and integrate various subjects in the value chain of manufacturing enterprises and their business activities, thus rapidly realizing personalized innovation while meeting the personalized demands of customers. The literature considered that the DT strategy is expected to use digital resources to generate a differentiated value [32]. To be specific, DT can facilitate the exchange of new ideas between manufacturing enterprises and their value chain partners, thus further improving, or innovating in, business processes and relevant products by manufacturing enterprises [14]. This DT can further improve the technological innovation performance of enterprises [14]. For example, a digital operation in Zara Company enables it to complete the entire process from design, garment manufacture, manual ironing, folding, hanging, and even automatic sorting and packing. The innovation allows Zara to put new goods on the shelves twice a week, greatly reducing product inventory (Wu Yuzheng, When everyone is talking about the digital transformation, how should we do it? http://mt.sohu.com/20170220/n481189637.shtml). In another example, through the cooperation with Huawei, Harley motorcycles realized the interconnection of all production lines, so that production management was accurate to specified tolerances within seconds. Each motorcycle, with approximately 1200 parts, can be assembled in $89 \mathrm{~s}$, and the time taken from customers placing orders on-line to 
delivery is reduced from 21 days to $6 \mathrm{~h}$ (Xu Zhijun, Digital transformation will become a strategic choice for all enterprises, http://www.kejixun.com/article/160901/217706.shtml). By integrating information, communications and technology (ICT), enterprises can successfully carry out DT, and then generate PSIP. Therefore, the hypothesis below is proposed:

Hypothesis 3a (H3a). The degree of DT is positively associated with PSIP.

The DT of manufacturing enterprises can further facilitate research and development of new products. DT can improve the independent ability of research and development of manufacturing enterprises and lead to the upgrading of competition formats [35]. For instance, based on DT, the Red Collar Group in China created the Kute intelligent customer-to-manufactory (C2M) business model and replaced manual clothing pattern making by a big data system. This large-scale personalized customization mode can be used to realize over millions of trillions of design combinations, covering 99.9\% of all possible personalized design demands (Billion euro, http://www.myzaker.com/article/ 58c673431bc8e05f36000009/). Eiteneyer et al. (2019) also found that web-mediated mechanisms transformed knowledge into tangible product innovativeness. Therefore, based on DT, manufacturing enterprises can promote PDI and meet personalized needs. In the sanitation sector, the literature also found that DT can enable advanced service [36]. Based on the above, the following hypothesis can be given:

Hypothesis $\mathbf{3 b} \mathbf{( H 3 b )}$. The degree of DT has a positive associated with PDIP.

Figure 1 shows our research model and related hypotheses.

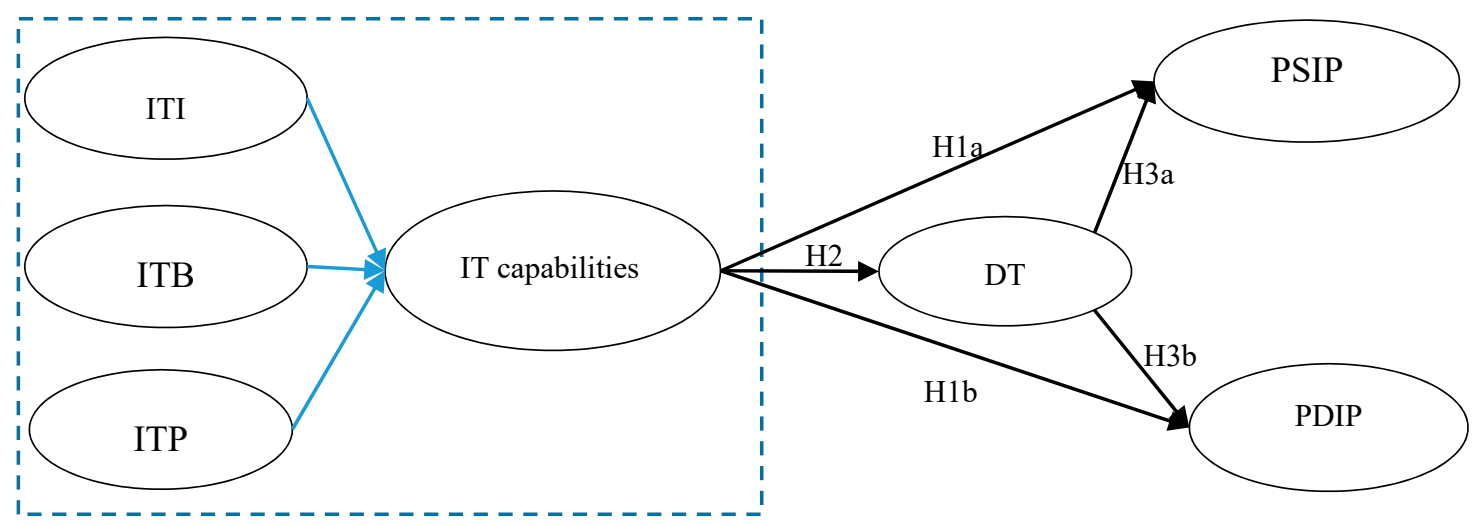

Figure 1. Research model.

\section{Research Design}

\subsection{Research Samples and Data Collection}

The research mainly gathered the data by performing a questionnaire investigation. IT/business executives and senior managers of five traditional manufacturing enterprises, such as Dongfeng Peugeot Citroen Automobile Co., Ltd. and McQuay Air Conditioners were interviewed. According to the survey feedback, in view of actual conditions around DT in manufacturing enterprises, relevant measurement indices in the questionnaire were improved.

A list of approximately 2000 qualified manufacturing firms in electronic machinery, utilities, transportation, metals, plastics, pharmaceuticals, healthcare and so forth was obtained from the Chinese Electronic Commerce Association and Commission of Economy and Information Technology. An industry stratified random sample of 500 firms was selected from the list. By using convenient sampling, the list of enterprises under investigation was determined and one questionnaire was issued to each enterprise. The questionnaires were required to be filled out by middle or senior managers in 
departments, such as the enterprise information department or operation management department. Under the supervision of telephone and e-mail communications, 149 questionnaires were collected within one month (a valid rate of $29.8 \%$ ). A total of 11 questionnaires were deleted owing to their being incomplete or providing identical answers. Therefore, a total of 138 valid questionnaires were obtained. These firms represented a wide variety of industries in China, and reflecting the average stage of economic reform and market formation in China. The sample characteristics are shown in Table 1.

Table 1. Sample characteristics $(N=138)$.

\begin{tabular}{lccccc}
\hline & No. & \% & & No. & $\%$ \\
\hline Industry & & & No. of Employees & & \\
Electronic machinery & 24 & 17.4 & $\leq 200$ & 27 & 19.6 \\
Utilities/Transportation & 31 & 22.5 & $201-500$ & 23 & 16.7 \\
Metals/Plastics & 32 & 23.2 & $501-1000$ & 29 & 21.0 \\
Pharmaceuticals/Healthcare & 28 & 20.3 & $1001-5000$ & 23 & 16.7 \\
Others & 23 & 16.7 & $>5000$ & 29 & 21.0 \\
Annual Revenue & & & Missing & 7 & 5.1 \\
<¥10 Million & 36 & 26.1 & Ownership type & & \\
$¥ 10-¥ 50$ Million & 21 & 15.2 & State owned & 38 & 27.5 \\
$¥ 50-¥ 100$ Million & 28 & 20.3 & Joint venture & 38 & 27.5 \\
$¥ 100-¥ 1000$ Million & 25 & 18.1 & Privately owned & 42 & 30.4 \\
$>¥ 1$ Billion & 18 & 13.0 & Foreign investment & 15 & 10.9 \\
Missing & 10 & 7.2 & Missing & 5 & 3.6 \\
\hline
\end{tabular}

The questionnaire returns from the surveyed enterprises in the early and late stages of the survey were compared to check for response bias in the survey samples. The statistical results indicated that the two groups of samples do not have significant statistical differences in terms of enterprise size, industry type and main variables $(p>0.1)$, therefore, there is no response bias in our study.

\subsection{Variables and Measurement}

The questionnaire mainly measures IT capabilities (including ITI, ITB, and ITP), DT and innovation performance (including PSIP and PDIP). For the purpose of guaranteeing reliability and validity of this questionnaire investigation, the measurement of the main constructs refers to the literature and also combines with the practices of the investigated enterprises. Based on a seven-point Likert scale, the subjects were requested to mark scores of 1 to 7 levels ( 1 and 7 separately denote strong disagreement and complete agreement) of their agreement with the description of each item. For some items in English, the study follows the procedures of translation and reverse-translation to ensure the accuracy of the questionnaire in translation. The specific items are listed in Table 2.

IT capabilities reflect the degree to which a manufacturing enterprise manages its IT resources to support business strategies and processes. In accordance with previous research [21], IT capabilities in this study comprise three dimensions: ITI, ITB, and ITP. By using a second-order reflective model, IT capabilities are measured. ITI emphasizes that enterprises can effectively deploy relevant hardware platforms and software systems and is mainly measured through two items: ITB stresses that enterprises can effectively support business objectives through IT resources and is measured using three items. Furthermore, ITP focuses on how enterprises can proactively utilize existing IT resources to create business opportunities and is measured by using three items (see Table 2).

DT is a construct developed in this study, which reflects the way in which enterprises can change and transform relying on digital technologies, that is, how traditional manufacturing enterprises transform to those based on big data, cloud computing and social platforms. According to research into digital business strategies [16,31,33], by combining this with practices of manufacturing enterprises in China, the Delphi method was utilized to carry out three rounds of iterations for the preliminarily designed items and finally determined three items for DT (see Table 2). 
Table 2. The results of factor scores.

\begin{tabular}{ccccccc}
\hline Item ID & ITB & ITP & DT & PSI & ITI & PDI \\
\hline ITB1 & $\mathbf{0 . 8 5 8}$ & 0.041 & 0.152 & 0.174 & 0.239 & 0.002 \\
ITB2 & $\mathbf{0 . 8 4 7}$ & 0.009 & 0.285 & 0.209 & 0.179 & -0.026 \\
ITB3 & $\mathbf{0 . 8 4 6}$ & 0.111 & 0.162 & 0.131 & 0.143 & 0.072 \\
ITP3 & -0.020 & $\mathbf{0 . 9 2 1}$ & 0.052 & 0.002 & 0.023 & -0.027 \\
ITP1 & 0.159 & $\mathbf{0 . 8 5 4}$ & 0.073 & 0.047 & 0.064 & 0.036 \\
ITP2 & 0.012 & $\mathbf{0 . 8 2 9}$ & 0.291 & 0.092 & 0.012 & 0.044 \\
DT3 & 0.132 & 0.191 & $\mathbf{0 . 8 4 3}$ & 0.129 & 0.039 & 0.161 \\
DT2 & 0.215 & 0.103 & $\mathbf{0 . 7 8 7}$ & 0.022 & 0.271 & 0.071 \\
DT1 & 0.278 & 0.155 & $\mathbf{0 . 7 4 8}$ & 0.216 & 0.188 & 0.067 \\
PSIP2 & 0.229 & 0.061 & 0.151 & $\mathbf{0 . 9 1 6}$ & 0.095 & -0.018 \\
PSIP1 & 0.197 & 0.066 & 0.128 & $\mathbf{0 . 9 1 6}$ & 0.194 & 0.015 \\
ITI2 & 0.222 & 0.084 & 0.185 & 0.149 & $\mathbf{0 . 9 0 8}$ & 0.054 \\
ITI1 & 0.307 & 0.009 & 0.234 & 0.170 & $\mathbf{0 . 8 6 7}$ & 0.103 \\
PDIP2 & 0.034 & 0.025 & 0.120 & 0.006 & 0.049 & $\mathbf{0 . 9 4 6}$ \\
PDIP1 & 0.007 & 0.014 & 0.101 & -0.008 & 0.074 & $\mathbf{0 . 9 4 5}$ \\
Eigenvalue & 5.449 & 2.229 & 1.880 & 1.204 & 1.035 & 1.001 \\
Explained variance $(\%)$ & 36.329 & 14.861 & 12.536 & 8.030 & 6.899 & 6.673 \\
Cronbach's $\alpha$ & 0.937 & 0.778 & 0.901 & 0.932 & 0.969 & 0.912 \\
\hline
\end{tabular}

Note: Orthogonal rotation is adopted and figures in bold have a factor load exceeding 0.5 .

Innovation performance highlights technological innovation and mainly comprises PSIP and PDIP. In accordance with previous research $[26,37,38]$, PSIP emphasizes the use of new or improved manufacturing and business processes in enterprises. PDIP involves research, development and the production of new products and services. This research measured PSIP and PDIP by using two items (see Table 2).

Furthermore, the characteristics of enterprises, such as the enterprise size (number of employees) and industry type, affect PSIP and PDIP and their use as control variables. The size of an enterprise is measured through ordinal variables of the numbers of employees, while the industry type is characterized by nominal variables.

\section{Data Analysis and Results}

\subsection{Reliability and Validity}

By employing SPSS22.0, an exploratory factor analysis was performed on all constructs by using the orthogonal rotation method with maximized variance. The Kaiser-Meyer-Olkin (KMO) statistic is greater than 0.80 and Bartlett's test of sphericity is considered passed at the significance level of 0.001 . All eigenvalues are greater than 1 and the cumulative variance explanation rate reaches $85.328 \%$, indicating that the whole factor structure is clear and preliminarily meets the basic standard of validity (Table 2). Moreover, Smart PLS 3.0 was used for a confirmatory factor analysis (CFA), so as to verify the convergent validity and discriminant validity. The results demonstrate that the factor load of all items exceeds 0.5 and is significant, and convergent validity preliminarily reaches the usual requirements (Table 3). In addition, the average variance extracted (AVE) exceeds 0.5 and the square root of AVE is expected to be a value larger than the correlation coefficient of the cross variables (Table 4). The discriminant validity in this study also reaches the required standard. Cronbach's $\alpha$ was used to calculate the reliability level of the scale and was between 0.778 and 0.969 . This is much larger than the threshold of 0.7 (Table 2). These results indicate that the reliability of the scale in this study is high. 
Table 3. Analysis of the construct measurement and convergent validity.

\begin{tabular}{|c|c|c|c|c|}
\hline Variable & ID & Item & Factor Loading & AVE \\
\hline \multirow{2}{*}{ ITI } & ITI1 & $\begin{array}{l}\text { IT hardware facilities supporting } \\
\text { the connection of various digital } \\
\text { platforms (such as, on-line } \\
\text { transactions) }\end{array}$ & 0.971 & \multirow{2}{*}{0.940} \\
\hline & ITI2 & $\begin{array}{l}\text { System software or functional } \\
\text { components supporting the } \\
\text { integration and extension of digital } \\
\text { platforms }\end{array}$ & 0.968 & \\
\hline \multirow{3}{*}{ ITB } & ITB1 & $\begin{array}{l}\text { Planning commercial activities } \\
\text { between enterprises supported } \\
\text { by IT }\end{array}$ & 0.917 & \multirow{3}{*}{0.833} \\
\hline & ITB2 & $\begin{array}{l}\text { Making application schemes of IT } \\
\text { system in commercial cooperation }\end{array}$ & 0.936 & \\
\hline & ITB3 & $\begin{array}{l}\text { Establishing effective cooperation } \\
\text { mechanisms by using IT resources }\end{array}$ & 0.884 & \\
\hline \multirow{3}{*}{ ITP } & ITP1 & $\begin{array}{l}\text { Developing new markets together } \\
\text { with partners through IT }\end{array}$ & 0.882 & \multirow{3}{*}{0.778} \\
\hline & ITP2 & $\begin{array}{l}\text { Making better use of internet-based } \\
\text { business opportunities }\end{array}$ & 0.877 & \\
\hline & ITP3 & $\begin{array}{l}\text { Strengthening information sharing } \\
\text { and realizing ability to faster } \\
\text { respond to market conditions } \\
\text { through IT }\end{array}$ & 0.886 & \\
\hline \multirow{3}{*}{ DT } & DT1 & $\begin{array}{l}\text { Supporting new commercial } \\
\text { activities by utilizing digital } \\
\text { technologies (such as big data, cloud } \\
\text { computing, and social platforms) }\end{array}$ & 0.856 & \multirow{3}{*}{0.751} \\
\hline & DT2 & $\begin{array}{l}\text { Integrating business process by } \\
\text { using digital technologies (such as } \\
\text { big data, cloud computing, } \\
\text { and social platforms) }\end{array}$ & 0.854 & \\
\hline & DT3 & $\begin{array}{l}\text { Supporting communication of } \\
\text { commercial information through } \\
\text { digital technologies (such as big } \\
\text { data, cloud computing, and social } \\
\text { platforms) }\end{array}$ & 0.891 & \\
\hline \multirow{2}{*}{ PSIP } & PSIP1 & $\begin{array}{l}\text { Establishing a new cooperative } \\
\text { business process (e.g., electronic } \\
\text { ordering) with partners }\end{array}$ & 0.966 & \multirow{2}{*}{0.932} \\
\hline & PSIP2 & $\begin{array}{l}\text { Realizing new strategies of } \\
\text { marketing innovation and } \\
\text { providing on-line sale and services }\end{array}$ & 0.964 & \\
\hline \multirow{2}{*}{ PDIP } & PDIP1 & $\begin{array}{l}\text { Accelerating new product } \\
\text { development through on-line } \\
\text { collaboration between enterprises }\end{array}$ & 0.951 & \multirow{2}{*}{0.912} \\
\hline & PDIP2 & $\begin{array}{l}\text { Enterprises constantly launching } \\
\text { value-added services or products } \\
\text { that are in line with demands of } \\
\text { customers }\end{array}$ & 0.959 & \\
\hline
\end{tabular}

Note: Items reach a significant level with a factor load exceeding 0.001 . 
Table 4. Mean, standard deviation, correlation coefficient and discriminant validity.

\begin{tabular}{ccccccc}
\hline Variable & $\mathbf{1}$ & $\mathbf{2}$ & $\mathbf{3}$ & $\mathbf{4}$ & $\mathbf{5}$ & $\mathbf{6}$ \\
\hline IT capabilities & $\mathbf{0 . 7 7 5}$ & & & & & \\
DT & $0.613^{* *}$ & $\mathbf{0 . 8 6 7}$ & & & & \\
PSIP & $0.456^{* *}$ & $0.362^{* *}$ & $\mathbf{0 . 9 6 5}$ & & & \\
PDIP & 0.139 & $0.239^{* *}$ & $0.130^{*}$ & $\mathbf{0 . 9 5 5}$ & & \\
Enterprise size & $0.233^{* *}$ & $0.207^{*}$ & 0.078 & 0.151 & 1 & 1 \\
Industry type & 0.067 & 0.105 & 0.024 & 0.052 & -0.082 & 3.949 \\
Mean & 5.018 & 5.080 & 4.588 & 4.730 & 4.912 & 1.606 \\
S.D. & 0.826 & 1.293 & 1.128 & 1.073 & 1.341 & \\
\hline
\end{tabular}

Note: ${ }^{*} p<0.05$ and ${ }^{* *} p<0.01$. Italics and bold numbers along the diagonal line indicate square roots of AVE.

\subsection{Common Method Bias}

To avoid a common method bias (CMB), the questionnaires were designed using the following procedure [39]: (1) developing clear and concise items and (2) collecting questionnaires anonymously. After the data collection, the following two methods were mainly used to test CMB. Firstly, by utilizing the marker variable test [40], the partial correlation coefficients of each variable were calculated by selecting an item with the lowest correlation coefficient (namely, industry type and PSIP). The results show that the correlation coefficients adjusted through $\mathrm{CMB}$ do not change significantly in comparison with the original values $(r \leq 0.045$ and $p>0.10)$. Furthermore, based on the correlation coefficients adjusted by using $\mathrm{CMB}$, the variations in the regression coefficients of the model can be obtained. The results show that the difference of the regression coefficients of IT capabilities and DT, before and after adjustment, changes from 0.02 to 0.05 (the differences are insignificant as evinced by the chi-squared test, $p>0.10$ ). Secondly, through the incorporation of a method factor with the measurement model [41], the potential impacts of $\mathrm{CMB}$ were also evaluated. The items with extremely low loads on the method factors compared with substantive factors were discovered. The method was found to be able to explain 0.023 of the variances in the dataset on average, along with a majority of insignificant loadings on the method factor. Based on the above analysis, no significant method bias arises.

\subsection{Hypothesis Test Using SEM}

The research hypotheses were verified by using structural equation modeling (SEM). At present, there are two main estimation methods of SEMs, namely, covariance-based SEM and variance-based SEM. Some researchers have posited that variance-based SEMs, such as partial least squares PLS-SEM, suffer from inconsistent estimation, however, PLS-SEM is more suitable for exploratory predictive research and can better process non-normal sample data. Furthermore, researchers have developed a consistent PLS (PLSc) method for estimation in recent years [42]. The estimation method adopts asymptotically normal estimators because they generally achieve consistent estimation. The core calculation method of PLSc is a two-stage least square method (2SLS), which can estimate each equation individually and relies only on limited information.

This research processed the data by using Smart PLS 3.0 software. To ensure consistency of the estimation, the consistent PLSs estimation method and PLSs bootstrapping $(N=5000)$ were separately used to estimate the coefficients and their significance of each path. Figure 2 illustrates the path coefficients and $R^{2}$ in the tests result obtained using the structural modeling. The explained variances of three dependent variables, i.e., DT, PSIP, and PDIP (separately) are $37.5 \%, 24.5 \%$ and $11.9 \%$. The two control variables (enterprise size and industry type) both have insignificant influences on PSIP and PDIP. The results indicate that except for $\mathrm{H} 1 \mathrm{~b}$, the other four hypotheses are all valid at the significance level of 0.05 (Figure 2). To be specific, IT capabilities significantly and positively affect PSIP $(\beta=0.429$; $p<0.001$ ), which verifies H1a. IT capabilities are found to have significant and positive effects on DT $(\beta=0.613 ; p<0.001)$, thus verifying H2. Furthermore, DT significantly and positively influence PSIP and PDIP, thus supporting both $\mathrm{H} 3 \mathrm{a}$ and $\mathrm{H} 3 \mathrm{~b}$. 


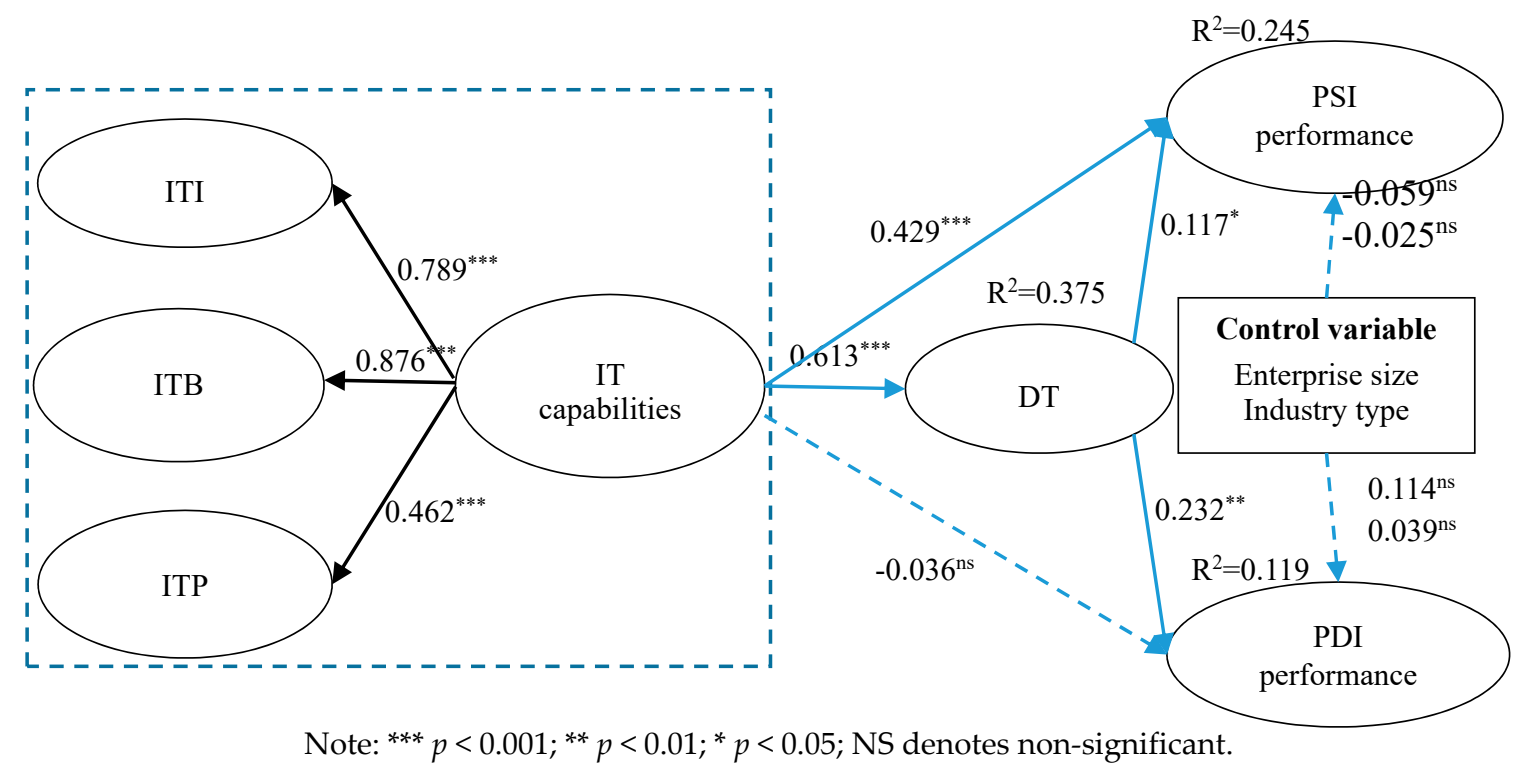

Figure 2. Research results.

\subsection{Further Validation Using $f_{s} Q C A$}

The above data employed in SEM were further adopted for conducting the fsQCA, which applied the necessity and sufficient conditions for the determinations based on memberships from 0 to 1 [43]. Recently, the fsQCA has been used by many investigations in the domain of information systems $[44,45]$ to respond to the emerging multiple realities and restrictions of symmetric statistical tests (i.e., the regression-based methods). The fsQCA consists of three subsequent steps: (1) the assignment of fuzzy-set membership scores to cases (also known as calibration), (2) the identification of necessary conditions and (3) the identification of sufficient configurations [46]. This study used the fsQCA 3.0 to complete all three steps.

\subsubsection{Calibration}

As fsQCA adopts a concept of set membership, the raw data have to be converted to fuzzy sets in a range of 0 to 1 (separately representing a full exclusion from a set and full inclusion) [46]. In the research, one index is calculated for each of constructs prior to the calibration of variables through averaging of corresponding indicators. Three anchors should be specified for the calibration process: a crossover point, full membership and full nonmembership [46]. As to all of the constructs (outcomes and conditions), the immediate approach to calibrate fuzzy sets was used on the basis of theoretical anchors [46]. Therefore, the rating of 7 represents full membership while that of 1 denotes full nonmembership in this paper. Following prior literature $[47,48]$, this study uses the mean value as the crossover point.

\subsubsection{Analysis of Necessary Conditions}

Despite the key to the fsQCA of studying enough conditions, it always needs to identify the necessary conditions at first [49]. This study explores the innovation performance (computing as the average of PSI performance and PDI performance) as outcomes. The same as in SEM and the fsQCA analysis also takes all antecedent conditions into account for returning the outcomes. For the purpose of determining whether innovation performance requires any of the four conditions, the conditions always present or absent in all cases with or without an outcome are studied. Thus, the innovation performance can be obtained once the questioned condition appears. The conforming degree of cases to the rule is known as consistency. One condition is regarded "almost always necessary" or "necessary" if its consistency score is separately higher than thresholds of 0.8 or 0.9 [50]. The results yielded in 
the fsQCA test on the necessity of conditions with respect to outcomes of innovation performance are presented in Table 5. The results show that digital transformation is a necessary condition for innovation performance. Thus, this study proceeds to present the results of the sufficiency analysis in Table 6.

Table 5. Configurations for achieving high innovation performance.

\begin{tabular}{cccc}
\hline \multirow{2}{*}{ Configuration Elements } & \multicolumn{3}{c}{ High Innovation Performance } \\
\cline { 2 - 4 } & HIP1 & HIP2 & HIP3 \\
\hline ITI & $\bullet$ & $\otimes$ & \\
ITB & $\bullet$ & & $\bullet$ \\
ITP & - & & \\
DT & - & 0.344 & 0.298 \\
Raw Coverage & 0.198 & 0.088 & 0.091 \\
Unique Coverage & 0.021 & 0.912 & 0.882 \\
Consistency & 0.877 & 0.565 & \\
Overall Solution Coverage & & 0.866 & \\
Overall Solution Consistency & & & \\
\hline
\end{tabular}

Notes: Black circles represent presence of a condition; Crossed-out circles represent absence of a condition; Empty rows denote that condition may be either present or absent; Large circles stand for core condition; Small circles stand for peripheral condition; Raw consistency cut-off: 0.85; PRI consistency cut-off: 0.75; Frequency cut-off: 4.

Table 6. Analysis of necessity and sufficiency.

\begin{tabular}{ccc}
\hline Conditions & Consistency & Coverage \\
\hline ITI & 0.772 & 0.845 \\
$\sim$ ITI & 0.547 & 0.492 \\
ITB & 0.821 & 0.844 \\
$\sim$ ITB & 0.633 & 0.786 \\
ITP & 0.885 & 0.877 \\
$\sim$ ITP & 0.754 & 0.687 \\
DT & 0.911 & 0.887 \\
$\sim$ DT & 0.787 & 0.855 \\
\hline
\end{tabular}

\subsubsection{Sufficient Conditions and Causal Recipes of High Innovation Performance}

Sufficient conditions are analyzed by constructing a truth table at first [46] which contains $2^{\mathrm{k}}$ rows where $\mathrm{k}$ represents the amount of conditions. Each row in the table corresponds to a configuration of conditions. Each row has correspondence to a condition configuration. Each observation is in a particular row in accordance with scores of set memberships. By employing the fsQCA algorithm, truth tables for the innovation performance were produced. For the purpose of decreasing truth tables so that they have meaningful configurations, a frequency threshold was adopted for four observations for excluding configurations of less importance. Meanwhile, it is also recommended in previous QCA literature that $80 \%$ of cases at the lowest in samples are supposed to remain after applying frequency restrictions [46]. By using the frequency threshold, it is guaranteed that $81.25 \%$ of cases in the samples are analyzed in terms of innovation performance. Afterwards, for the identification of configurations that are enough for obtaining outcomes, a consistency threshold larger than 0.85 is used. Moreover, on conditions that these threshold values are applied, three solutions are yielded by the fsQCA software: intermediate, parsimonious and complex solutions. Coverage and consistency values of each complex solution and the corresponding configurations exceed minimum values that are acceptable [46].

Table 5 reports the configurations results using the notation system from prior research [48]. The second column to the fourth column in this table (e.g., HIP1, HIP2 and HIP3) denote a condition configuration, corresponding to a recipe for the intermediate solution. By illustrating the configurations as graphs in Table 5, complicated structures of configurations can be more effectively interpreted and 
compared in a certain manner. The manner can explain how the elements are combined systemically and simultaneously to gain roles and outcomes of all elements in the dynamics associated with obtaining high innovation performance. Hence, as opposed to traditional approaches like a cluster analysis, the fsQCA assesses connections of elements and their roles of a configuration with sufficient detail to obtain high innovation performance and constructs a systemic middle-range theory, in addition to allowing one to devise clusters of high innovation performance $[43,48]$. According to the Table 7 , it can be seen that there are three configurations which can be adopted by organizations for realizing high innovation performance, suggesting the case of equifinality. (1) Configuration HIP1, both ITP and DT as core elements and both ITI and ITB as peripheral elements can support firms to achieve high innovation performance. (2) Configuration HIP2, both ITP and DT as core elements can enable high innovation performance. (3) Configuration HIP3, both ITB and DT as core elements and ITP as a peripheral element can achieve high innovation performance. These further confirmed our findings in the SEM.

Table 7. Bootstrapping results showing the mediating effects of digital transformation (DT).

\begin{tabular}{cccccc}
\hline \multirow{2}{*}{ Dependent Variable } & Type of Effect & \multirow{2}{*}{ Effect Size } & \multirow{2}{*}{ S.E. } & \multicolumn{2}{c}{ 95\% Confidence Interval } \\
\cline { 5 - 6 } & & & & LLCI & ULCI \\
\hline \multirow{2}{*}{ PDIP } & Indirect effect & 0.2054 & 0.1240 & 0.0029 & 0.5009 \\
& Direct effect & -0.0158 & 0.1448 & -0.3023 & 0.2706 \\
\multirow{2}{*}{ PSIP } & Indirect effect & 0.1265 & 0.0334 & 0.0938 & 0.3909 \\
& Direct effect & 0.5877 & 0.1511 & 0.2888 & 0.8866 \\
\hline
\end{tabular}

\subsection{Robustness Tests}

Robustness tests include the tests of mediating effects, the reverse causality test, the correlation test between subjective PDIP and the objective patent number. Firstly, in reference to Preacher and Hayes [51] as well as the bootstrapping method proposed by Hayes [52], the mediating effects of the two paths were tested separately using an SPSS Process macro-program on a sample size of 5000. (1) In both paths from IT capabilities to DT and PSIP, at the 95\% confidence interval, zero is not included in the results of the mediating test (lower limit of the confidence interval (LLCI) and the upper limit of the confidence interval (ULCI) are 0.0938 and 0.3909 , respectively), indicating that the mediating effects of DT are significant and the mediating effect size is 0.1265 . In addition, after controlling the mediating variable DT, IT capabilities significantly affect PSIP and 0 are not included in the interval (LLCI $=0.2888$ and ULCI $=0.8866$ ), therefore, DT plays a partial mediating role between IT capabilities and PSIP. (2) In both paths from IT capabilities to DT and PDIP, at the 95\% confidence level, the results of the mediating test do not include $0(\mathrm{LLCI}=0.0029$ and ULCI $=0.5009)$, demonstrating that the mediating effects of DT are significant and the mediating effect size is 0.2054 . Moreover, after controlling for the mediating variable (DT), the independent variable (IT capabilities) exerts no significant influences on the dependent variable (PDIP) and 0 is included in the interval (LLCI $=-0.3023$ and ULCI $=0.2706$ ). Therefore, DT plays a complete mediating role between IT capabilities and PDIP (see Table 7).

Secondly, this study tested the possible risks of reverse causality, that is, whether DT had any adverse effects on IT capabilities and could possibly cause endogenous problems. In this research, reverse causality in the research model was analyzed using the two-stage Heckman test $[10,53]$ as follows: (1) An analysis of the regression coefficients and $R^{2}$ of IT capabilities and DT (model 1), and (2) performing the two-stage Heckman test. IT capabilities are firstly grouped by the median, and those exceeding the median are set to 1 , otherwise 0 . Moreover, the regression coefficients of DT on IT capabilities were calculated using a Probit model (model 2). The data results demonstrate that DT significantly and positively affects IT capabilities $(p<0.05)$, so there is a risk of reverse causality. (3) By employing STATA 13.0, the inverse Mills ratio was calculated and incorporated into the regression model (model 3) together with IT capabilities. In comparison with model 1, the regression coefficients 
of IT capabilities in model 3 do not change significantly, therefore, although the research model incurs a risk of reverse causality, the results arising from the use of the PLS structural equations remain robust.

Thirdly, to verify the validity of subjective PDIP, this study adopted the correlation coefficients to test the correlation between the subjective PDIP and the objective patent number (including Patents for Inventions, for Utility Models and for Appearance Design) [54] as follows: (1) A total of 86 enterprises matching the list of participant enterprises in this study were extracted from the Wanfang patent database in China. (2) This study collected relevant data of objective patents of these 86 enterprises in the year ( $t$ year) collecting the questionnaire and the previous two years' data. (3) The Pearson correlation between PDIP and the objective patent number was analyzed, and the average correlation coefficient reached $0.41(p<0.05)$. This indicates that subjective PDIP in this study relatively, objectively and accurately measured the innovation performance.

Additional tests were also performed for verification of the robustness of the models with different choices for calibration in the fsQCA. Firstly, the thresholds of full membership and full nonmembership (i.e., 6.75 rather than 7 and 1.25 rather than 1 to be completely in and out the set) were altered and two outcomes were analyzed again. Identical results were obtained in the analysis (as shown in Table 7). Secondly, the crossover point also changed to $3.75,4$ and 4.25 in the different analyses from the initial mean value. The accordant results yielded over these analyses of innovation performance. The analysis with a higher threshold (i.e., 0.95) of consistency was finally replicated. The solutions, as expected, have higher consistency and lower coverage, and represent one perfect subset of initial solutions [49]. The above results of multiple analyses verify the robustness of our findings.

\section{Discussion and Implications}

\subsection{Research Implications}

By investigating and studying 138 manufacturing enterprises in China in this research, this study found that IT capabilities have positive impacts on PSIP and DT, and DT exert positive impacts on PSIP and PDIP. Of these, DT plays a partial mediating role between IT capabilities and PSIP, while a full mediating role between IT capabilities and PDIP. This research deepens the theoretical understanding of the relationships of IT capabilities, DT, PSIP and PDIP, and provides relevant guidance for IT management and innovation management in manufacturing enterprises. The following research implications follow from our study.

Firstly, based on three dimensions of IT capabilities, i.e., ITI, ITB, and ITP, the IT capabilities of the enterprises were measured in the digital environment. Moreover, by using the second-order reflective model, the positive effects of IT capabilities on DT and PSIP were verified. In previous literature, IT capabilities of enterprises are mainly measured based on relevant indices extracted from the objective scale $[18,55]$ or obtained through questionnaires collected from enterprise managers. The relevant items from the objective scale are mainly standardized ITI capabilities (such as data acquisition systems and network linking [7]), while the data related to IT management capabilities are difficult to obtain accurately. Consistent with the prior research [21], this study verifies the validity and rationality of measuring IT capabilities of enterprises from the aforementioned three aspects (ITI, ITB, and ITP) by applying the data relating to manufacturing enterprises in China. In addition, this study verified that IT capabilities show positive effects on DT and PSIP.

Secondly, this study designed and measured constructs of DT among manufacturing enterprises and found that the partial mediating role of DT improved the specific effect mechanisms of IT capabilities on PSIP. Previous research mainly explores the effects of IT capabilities on process innovation [10], while paying insufficient attention to the specific process (for example, the effects of DT are neglected) [15]. Through a case study involving Volvo cars, researchers found that innovation capabilities can be realized by building a social platform, performing asset assessments, and implementing the Volvo Cloud [6]. Under the background of DT in enterprises, this study verified 
that IT capabilities of manufacturing enterprises promote DT by utilizing a quantitative empirical research method, thus realizing the mechanisms of action of PSIP.

Thirdly, the full mediating role of DT explains the key effects of DT in realizing product innovation, that is, IT capabilities have differentiated the effects on the two technological innovation performances. For PDIP, IT capabilities can be produced through DT. Apart from affecting PSIP through DT, IT capabilities can also directly produce PSIP. This is basically consistent with previous research. For instance, by analyzing nine years of panel data from manufacturing enterprises in Switzerland, Trantopoulos et al. found that coordinated purchasing of external knowledge and IT investment can promote PSI and enterprise performance. However, in the prior literature, the innovation performance of an enterprise is mainly studied as a whole construct (such as, the number of patents) [16], while such effects of differentiation are not found. In light of $\mathrm{H} 1 \mathrm{~b}$ having been rejected, a possible explanation is that PDIP imposes higher digitization requirements on enterprises in comparison with PSI. PDIP cannot occur before the formation of comprehensive digitization and automation after manufacturing companies carry out DT. However, the initial reconstruction of business processes, that is, PSI can be promoted only by calling for the cultivation of IT capabilities [7].

Finally, the study found that the fsQCA is applicable to investigate the configurations of innovation performance. Previous investigations of the subject are commonly dependent on regression-based methodology and regard innovation performance mainly as outcomes of numerous individual factors. By using the fsQCA, the combination of IT capabilities and digital transformation factors generating innovation performance can be analyzed, therefore, the fsQCA provides a way of coping with high causal complexity $[43,45]$. The fsQCA provides results with significant theoretical insights concerning the mechanism for forming innovation performance. First, by using the fsQCA, the diverse causal paths with equifinality of innovation performance are revealed. This is a significant fact that is not sufficiently accounted for in previous literature dependent on a traditional statistical analysis like regression-based methodology (i.e. SEM). Three configurations are provided in the results for achieving high-level innovation performance. The conclusion is consistent with our SEM findings. Therefore, by adopting the fsQCA, a solution of higher comprehensiveness is provided for the functions of the three IT capabilities and digital transformation for the formation of innovation performance.

\subsection{Management Implications}

This research has important policy and management implications for the implementation of Industry 4.0 and DT strategies of manufacturing enterprises. Firstly, from the perspective of IT management, DT needs enterprises to build excellent IT capabilities. The establishment of such capabilities mainly focuses on three aspects: ITI, ITB and ITP. Only when enterprise managers invest in, and construct, human resources and financial resources in the three dimensions of IT capabilities for the long-term can enterprises then realize DT. For instance, the Haier Group in China has renamed its IT department to reflect its role as a digital technology service (DTS) and actively promotes measures, such as the integration of person and order, marketization of the members of staff, and the participation of the user community in research and development, to implement DT.

Secondly, in terms of innovation management, DT can bring about technological innovation performance in an enterprise. For product innovation, the DT of manufacturing enterprises is the only route to the desired end, therefore, firm managers are expected to have consciousness of important influences of DT on innovation performance and actively utilize IT capabilities and other organizational resources to promote DT [7] (such as carrying out intelligent manufacturing [56]) among enterprises. The aim is to realize enterprise innovation and implement the Industry 4.0 policy to thus boost the transformation and upgrading of traditional manufacturing industries in China.

Finally, governments need to create the institutional environment necessary for DT among enterprises. On the one hand, governments should invest more in public digital technology resources (such as, construction of regional cloud computing centers), so as to provide a resource base for manufacturing enterprises to allow them to enact DT. On the other hand, governments should guide 
enterprises towards garnering the experience from enterprises which have succeeded in DT to facilitate the construction of internal IT capabilities, thus successfully realizing DT. For instance, the Red Collar Group in China provides a sample of digital solutions to traditional low-end manufacturing enterprises.

\subsection{Limitations and Further Research}

This study combined a variety of methods to guarantee the research to be valid and reliable and conducted additional robustness tests, thus verifying the research model. However, there are also limitations remaining to be explored. Firstly, the dataset of this study was from an Asian country. Additional data from western countries (for instance, U.S.) can be beneficial in terms of validating and generalizing the results in multiple research contexts. Secondly, for the antecedents of DT, this research is mainly based on IT capabilities while there are some other factors affecting DT, such as a firm's business strategies. In future work, these factors can be considered for the inclusion into our models. Thirdly, further research also can explore how DT can promote financial performance through both process and product innovation. Finally, the relationships between IT capabilities, DT and innovation performance were mainly analyzed on the basis of cross-sectional data, while in the future, an analysis of causality of variables can be further improved by means of a longitudinal study based on multisource data (for example, integrated both first-hand and second-hand data).

Author Contributions: Conceptualization, M.C. and W.W.; Methodology, Y.C.; Software and Formal analysis, Y.C. and M.C.; Writing - original draft preparation, Y.C. and M.C.; Writing-review and editing, M.C. and B.L.; Funding acquisition, W.W. and B.L.

Funding: This research has been supported by grants from the National Natural Science Foundation of China under Grant 71801104 and the National Social Science Foundation of China under Grant 18CTQ025.

Acknowledgments: We thank the anonymous reviewers for their constructive comments.

Conflicts of Interest: The authors declare no conflict of interest.

\section{References}

1. Szalavetz, A. Industry 4.0 and capability development in manufacturing subsidiaries. Technol. Forecast. Soc. Chang. 2019, 145, 384-395. [CrossRef]

2. Santos, M.Y.; Sa, J.E.; Andrade, C.; Lima, F.V.; Costa, E.; Costa, C.; Martinho, B.; Galvao, J. A Big Data system supporting Bosch Braga Industry 4.0 strategy. Int. J. Inf. Manag. 2017, 37, 750-760. [CrossRef]

3. Savastano, M.; Amendola, C.; Bellini, F.; D'Ascenzo, F. Contextual Impacts on Industrial Processes Brought by the Digital Transformation of Manufacturing: A Systematic Review. Sustainability 2019, 11, 891. [CrossRef]

4. Frank, A.G.; Mendes, G.H.S.; Ayala, N.F.; Ghezzi, A. Servitization and Industry 4.0 convergence in the digital transformation of product firms: A business model innovation perspective. Technol. Forecast. Soc. Chang. 2019, 141, 341-351. [CrossRef]

5. Hsu, C.-C.; Tsaih, R.-H.; Yen, D. The Evolving Role of IT Departments in Digital Transformation. Sustainability 2018, 10, 3706. [CrossRef]

6. Svahn, F.; Mathiassen, L.; Lindgren, R. Embracing Digital Innovation in Incumbent Firms: How Volvo Cars Managed Competing Concerns. Mis Q. 2017, 41, 239-253. [CrossRef]

7. Trantopoulos, K.; von Krogh, G.; Wallin, M.W.; Woerter, M. External Knowledge and Information Technology: Implications for Process Innovation Performance. Mis Q. 2017, 41, 287-300. [CrossRef]

8. Verstegen, L.; Houkes, W.; Reymen, I. Configuring collective digital-technology usage in dynamic and complex design practices. Res. Policy 2019, 48, 103696. [CrossRef]

9. Mention, A.-L.; Barlatier, P.-J.; Josserand, E. Using social media to leverage and develop dynamic capabilities for innovation. Technol. Forecast. Soc. Chang. 2019, 144, 242-250. [CrossRef]

10. Saldanha, T.; Mithas, S.; Krishnan, M.S. Leveraging Customer Involvement for Fueling Innovation: The Role of Relational and Analytical Information Processing Capabilities. Mis Q. 2017, 41, 267-286. [CrossRef]

11. Benner, M.J.; Tushman, M.L. Reflections on the 2013 Decade Award—“Exploitation, Exploration, and Process Management: The Productivity Dilemma Revisited" Ten Years Later. Acad. Manag. Rev. 2015, 40, 497-514. [CrossRef] 
12. Constantinides, P.; Henfridsson, O.; Parker, G.G. Introduction-Platforms and Infrastructures in the Digital Age. Inf. Syst. Res. 2018, 29, 381-400. [CrossRef]

13. Henfridsson, O.; Mathiassen, L.; Svahn, F. Managing technological change in the digital age: The role of architectural frames. J. Inf. Technol. 2014, 29, 27-43. [CrossRef]

14. Nambisan, S.; Wright, M.; Feldman, M. The digital transformation of innovation and entrepreneurship: Progress, challenges and key themes. Res. Policy 2019, 48, 103773. [CrossRef]

15. Nambisan, S.; Lyytinen, K.; Majchrzak, A.; Song, M. Digital Innovation Management: Reinventing Innovation Management Research in a Digital World. Mis Q. 2017, 41, 223-238. [CrossRef]

16. Nwankpa, J.K.; Roumani, Y. IT Capability and Digital Transformation: A Firm Performance Perspective. In Proceedings of the ICIS 2016, Dublin, Ireland, 11-14 December 2016.

17. Díaz-Chao, Á.; Sainz-González, J.; Torrent-Sellens, J. ICT, innovation, and firm productivity: New evidence from small local firms. J. Bus. Res. 2015, 68, 1439-1444. [CrossRef]

18. Bharadwaj, A.S. A resource-based perspective on information technology capability and firm performance: An empirical investigation. Mis Q. 2000, 24, 169-196. [CrossRef]

19. Wade, M.; Hulland, J. Review: The resource-based view and information systems research: Review, extension, and suggestions for future research. Mis Q. 2004, 28, 107-142. [CrossRef]

20. Barney, J. Firm resources and sustained competitive advantage. J. Manag. 1991, 17, 99-120. [CrossRef]

21. Lu, Y.; Ramamurthy, K.R. Understanding the Link Between Information Technology Capability and Organizational Agility: An Empirical Examination. Mis Q. 2011, 35, 931-954. [CrossRef]

22. Damanpour, F. Organizational Innovation: A Meta-Analysis Of Effects Of Determinants and Moderators. Acad. Manag. J. 1991, 34, 555-590.

23. Damanpour, F.; Szabat, K.A.; Evan, W.M. The Relationship Between Types of Innovation and Organizational Performance. J. Manag. Stud. 1989, 26, 587-602. [CrossRef]

24. Daft, R.L. A Dual Core Model of Organizational Innovation. Acad. Manag. J. 1978, 21, 193-210.

25. Xu, J.; Shang, Y.; Yu, W.; Liu, F. Intellectual Capital, Technological Innovation and Firm Performance: Evidence from China's Manufacturing Sector. Sustainability 2019, 11, 5328. [CrossRef]

26. Jiménez-Jiménez, D.; Sanz-Valle, R. Could HRM support organizational innovation? Int. J. Hum. Resour. Manag. 2008, 19, 1208-1221. [CrossRef]

27. Lyver, M.; Lu, T.-J. Sustaining Innovation Performance in SMEs: Exploring the Roles of Strategic Entrepreneurship and IT Capabilities. Sustainability 2018, 10, 442. [CrossRef]

28. Lindič, J.; Baloh, P.; Ribière, V.M.; Desouza, K.C. Deploying information technologies for organizational innovation: Lessons from case studies. Int. J. Inf. Manag. 2011, 31, 183-188. [CrossRef]

29. Libert, B.; Beck, M.; Wind, Y. 7 Questions to ask before your next digital transformation. Harv. Bus. Rev. 2016, 60, 11-13.

30. Westerman, G.; Soule, D.L.; Eswaran, A. Building Digital-Ready Culture in Traditional Organizations. Mit Sloan Manag. Rev. 2019, 60, 59-68.

31. Aral, S.; Weill, P. IT assets, organizational capabilities, and firm performance: How resource allocations and organizational differences explain performance variation. Organ. Sci. 2007, 18, 763-780. [CrossRef]

32. Bharadwaj, A.; El Sawy, O.A.; Pavlou, P.A.; Venkatraman, N. Digital Business Strategy: Toward A Next Generation of Insights. Mis Q. 2013, 37, 471-482. [CrossRef]

33. Mithas, S.; Tafti, A.; Mitchell, W. How a firm's competitive environment and digital strategic posture influence digital business strategy. Mis Q. 2013, 37, 511-536. [CrossRef]

34. Gupta, S. Driving Digital Strategy: A Guide to Reimagining Your Business; Harvard Business Review Press: Boston, MA, USA, 2018.

35. Eiteneyer, N.; Bendig, D.; Brettel, M. Social capital and the digital crowd: Involving backers to promote new product innovativeness. Res. Policy 2019, 48, 103744. [CrossRef]

36. Saul, C.; Gebauer, H. Digital Transformation as an Enabler for Advanced Services in the Sanitation Sector. Sustainability 2018, 10, 752. [CrossRef]

37. Datta, P.; Roumani, Y. Knowledge-acquisitions and post-acquisition innovation performance: A comparative hazards model. Eur. J. Inf. Syst. 2015, 24, 202-226. [CrossRef]

38. Wu, S.J.; Melnyk, S.A.; Flynn, B.B. Operational Capabilities: The Secret Ingredient. Decis. Sci. 2010, 41, 721-754. [CrossRef] 
39. Podsakoff, P.M.; MacKenzie, S.B.; Lee, J.Y.; Podsakoff, N.P. Common method biases in behavioral research: A critical review of the literature and recommended remedies. J. Appl. Psychol. 2003, 88, 879-903. [CrossRef]

40. Lindell, M.K.; Whitney, D.J. Accounting for common method variance in cross-sectional research designs. J. Appl. Psychol. 2001, 86, 114-121. [CrossRef]

41. Liang, H.; Wang, N.; Xue, Y.; Ge, S. Unraveling the Alignment Paradox: How Does Business-IT Alignment Shape Organizational Agility? Inf. Syst. Res. 2017, 28, 863-879. [CrossRef]

42. Dijkstra, T.K.; Henseler, J. Consistent Partial Least Squares Path Modeling. Mis Q. 2015, 39, $297-316$. [CrossRef]

43. Fiss, P.C. A Set-Theoretic Approach to Organizational Configurations. Acad. Manag. Rev. 2007, 32, 1180-1198. [CrossRef]

44. Park, Y.; Mithas, S. Organized Complexity of Digital Business Strategy: A Configurational Perspective. MIS Q. 2019, in press.

45. Park, Y.; Sawy, O.A.E.; Fiss, P.C. The Role of Business Intelligence and Communication Technologies in Organizational Agility: A Configurational Approach. J. Assoc. Inf. Syst. 2017, 18, 648-686. [CrossRef]

46. Ragin, C.C. Redesigning Social Inquiry: Fuzzy Set and Beyond; University of Chicago Press: Chicago, IL, USA, 2008.

47. Bell, R.G.; Filatotchev, I.; Aguilera, R.V. Corporate Governance and Investors' Perceptions of Foreign IPO Value: An Institutional Perspective. Acad. Manag. J. 2014, 57, 301-320. [CrossRef]

48. Fiss, P.C. Building Better Causal Theories: A Fuzzy Set Approach to Typologies in Organization Research. Acad. Manag. J. 2011, 54, 393-420. [CrossRef]

49. Schneider, C.Q.; Wagemann, C. Standards of Good Practice in Qualitative Comparative Analysis (QCA) and Fuzzy-Sets. Comp. Sociol. 2010, 9, 397-418. [CrossRef]

50. Ragin, C.C. Fuzzy Set Social Science; University of Chicago Press: Chicago, IL, USA, 2000.

51. Preacher, K.J.; Hayes, A.F. Asymptotic and resampling strategies for assessing and comparing indirect effects in multiple mediator models. Behav. Res. Methods 2008, 40, 879-891. [CrossRef]

52. Hayes, A.F. Introduction to Mediation, Moderation, and Conditional Process. Analysis: A Regression-Based Approach; Guiford Press: New York, NY, USA, 2013; pp. 335-337.

53. Bharadwaj, S.; Bharadwaj, A.; Bendoly, E. The Performance Effects of Complementarities Between Information Systems, Marketing, Manufacturing, and Supply Chain Processes. Inf. Syst. Res. 2007, 18, 437-453. [CrossRef]

54. Wu, S.P.-J.; Straub, D.W.; Liang, T.-P. How Information Technology Governance Mechanisms and Strategic Alignment Influence Organizational Performance: Insights from a Matched Survey of Business and IT Managers. Mis Q. 2015, 39, 497-518. [CrossRef]

55. Chae, H.C.; Koh, C.E.; Prybutok, V.R. Information Technology Capability and Firm Performance: Contradictory Findings and Their Possible Causes. Mis Q. 2014, 38, 305-326. [CrossRef]

56. Chick, S.E.; Huchzermeier, A.; Netessine, S. Europe's solution factories. Harv. Bus. Rev. 2014, 92, 111-115. 